\title{
Terminated Interventional Trials in the Clinical Trial Registry of India Database: An Analysis to Evaluate the Reasons for Termination
}

This article was published in the following Dove Press journal: Open Access Journal of Clinical Trials

\author{
Siddhartha Dutta $\mathbb{1 D}^{\prime}$ \\ Rimplejeet Kaur (D) ${ }^{2}$ \\ Mainul Haque (D) ${ }^{3}$ \\ Pankaj Bhardwaj (D) 4 \\ Deepak Saxena (iD ${ }^{5}$ \\ Nor Azlina A Rahman (iD ${ }^{6}$ \\ Halyna Lugova (iD) ${ }^{7}$ \\ Dilshad Jahan (iD) ${ }^{8}$ \\ Salequl Islam (iD) ${ }^{9}$ \\ Tajkera Sultana Chowdhury (iD) ${ }^{10}$ \\ Jaykaran Charan (D) \\ 'Department of Pharmacology, All India \\ Institute of Medical Sciences, Jodhpur, \\ Rajasthan, India; ${ }^{2}$ Department of Pharmacology, \\ Dr. S.N Medical College, Jodhpur, Rajasthan, \\ India; ${ }^{3}$ The Unit of Pharmacology, Faculty of \\ Medicine and Defence Health Universiti \\ Pertahanan, Nasional Malaysia (National \\ Defence University of Malaysia), Kuala Lumpur, \\ Malaysia; ${ }^{4}$ Department of Community and \\ Family Medicine, All India Institute of Medical \\ Sciences (AIIMS), Jodhpur, Rajasthan, India; \\ ${ }^{5}$ Indian Institute of Public Health (IIPH) \\ Gandhinagar, Gujarat, India; ${ }^{6}$ Department of \\ Physical Rehabilitation Sciences, Kulliyyah of \\ Allied Health Sciences, International Islamic \\ University Malaysia, Kuantan, Malaysia; ${ }^{7}$ The Unit \\ of Community Medicine, Faculty of Medicine and \\ Defence Health, National Defence University of \\ Malaysia, Kuala Lumpur, Malaysia; ${ }^{8}$ Department of \\ Hematology, Gandaria Beside Dhupkhola, Asgar \\ Ali Hospital Ltd, Dhaka, I204, Bangladesh; \\ ${ }^{9}$ Department of Microbiology, Jahangirnagar \\ University, Savar, Dhaka I342, Bangladesh; \\ ${ }^{10}$ Department of Urology, Shaheed Suhrawardy \\ Medical College Hospital, Dhaka I207, Bangladesh
}

Correspondence: Mainul Haque

The Unit of Pharmacology, Faculty of Medicine and Defence Health Universiti Pertahanan, Nasional Malaysia (National Defence University of Malaysia), Kem Perdana Sungai Besi, Kuala Lumpur 57000 , Malaysia

Tel +60 109265543

Email runurono@gmail.com
Background: Clinical Trial Registry - India (CTRI) is a valuable tool to access information regarding clinical trials conducted in India. To serve this purpose, the information provided on it must be complete and accurate. The present study was designed to assess the reasons for premature termination of clinical trials on the CTRI database and determine the average timings related to updating information on CTRI.

Methods: The data were extracted from the website of Clinical Trial Registry - India; all the terminated trials from 20 July 2007 to 18 December 2019 were included. The reasons given for termination were categorized as scientific reasons, nonscientific reasons, and unspecified reasons.

Results: Of 16,579 interventional clinical trials, 243 trials were terminated. Out of these 243 trials, reasons were given in 50 (20.58\%). In reasoning with scientific data, the most common reason was safety issues (14\%), and among nonscientific data, a significant delay in recruitment was a principal reason $(16 \%)$. The median time from date of registration to date of modification was 1034 days (0-3912), and the median time from the date of last revision to the date of our analysis was 1329 days (2-3138).

Conclusion: The reasons for termination are not mentioned adequately for the terminated clinical trials in the Clinical Trial Registry of India. Efforts need to be done to motivate investigators to report the reasons for termination. Proper planning of trial before initiation may prevent premature termination of clinical trials and ensure fair use of resources.

Keywords: Clinical Trial Registry of India, terminated trials, reasons for premature termination

\section{Introduction}

Clinical trials are a type of future research designed in an organized manner to evaluate the effect of interventions (drugs, vaccines, other therapies, or new ways of using existing treatments, surgical procedure, or dietary change) on human health outcomes. ${ }^{1}$ Randomized control trials (RCT) are considered a gold standard of evidence for establishing medical interventions' safety and efficacy. ${ }^{2}$ RCTs have been a crucial component in the drug discovery and development programs and are considered robust method to evaluate whether a new molecule is useful and safe in the treatment or prophylaxis of a particular disease. Though the evolution of clinical trial has been long enough and has been recorded back in biblical descriptions from $500 \mathrm{BC}$ but first controlled clinical trial of the modern era is considered to be conducted by British naval surgeon James Lind for scurvy treatment in $1747 .{ }^{3,4}$ In 
the current era of evidence-based medicine (EBM), where therapeutic management is wholly based on proven evidence, RCTs have been considered one of the most substantial evidence levels. They are a crucial component in EBM practice. ${ }^{5}$ Refinement and up-grading in the therapeutic regimens are currently based on the clinical trials' findings, which ultimately benefit mankind. Conducting RCTs is not an easy task but is quite challenging as it involves significant investments in the form of human subjects, financial, regulatory, and physical resources. It has multiple stakeholders, including the researchers, patients, funding agencies, pharmaceutical companies, ethics committees, and regulatory bodies, and managing them all is an intricate task. ${ }^{6}$ All the fact mentioned above makes it imperative to maintain transparency and accountability in clinical trials' conduction. The lack of transparency in these trials can have severe consequences on the patients and healthcare systems. Maintaining data transparency can help other qualified researchers to reevaluate and validate clinical trial results, remove inconsistencies, improve the effectiveness, and prevent duplication of the research. Access to all the detail regarding the trial can help build public trust in clinical research and the healthcare industry. ${ }^{7}$ Thus, several countries, including India, have developed online clinical trial registration online platform to register the clinical trials. ${ }^{8}$

The Clinical Trial Registry of India (CTRI) is a centralized clinical trial registry of India. All the clinical trials conducted in the country are to be registered prospectively to maintain transparency, accountability, and assess the clinical trial data. ${ }^{8}$ With time, the CTRI has become a valuable and informative database for the patients, researchers, regulatory authorities, and other bodies interested in research. ${ }^{9}$ To serve its mandate, the research is expected to provide correct, complete, and updated information on CTRI regarding their studies. ${ }^{8}$ Several studies conducted on various clinical trial registries have reported that the prematurely terminated trials' information is incomplete and not updated. ${ }^{10}$ The premature termination of clinical trials raises huge ethical, scientific, regulatory, and economic concerns as many invaluable resources are at stake. ${ }^{6,11}$ The trial's termination is justified if its termination is due to efficacy and safety issues rather than several avoidable reasons to prevent undue wastage of valuable resources. $^{11,12}$ The typical concerns regarding the terminated trials include the wastage of resources on unproductive research that might have been otherwise spent on other useful and productive ventures; the scientific issue that probably the study was not well planned or designed, which can lead to a low enrollment rate because the proper evaluation of the availability of study subjects was not done before initiating the study and the ethical concern that the study subjects which were enrolled before termination did not gain anything through participation. ${ }^{6,12,13}$

Since the CTRI is a robust database to extract the clinical trials' information, it is crucial to ensure that researchers' information on the CTRI database is not just due to compulsion for registration. It is taken as a responsibility to show accountability and transparency, particularly in case of terminated trial, which would help other prospective researchers to plan the study, accordingly, keeping in mind the pitfalls of the previous studies. Thus, in case of termination of trials, the reason for termination, the number of patients enrolled before termination, any publication of data before ending should be updated on the CTRI from time to time to enhance clarity. Thus, the present cross-sectional descriptive study was designed to explore whether the terminated trials give pertinent information on India's clinical trial registry. The objectives of the present study are: to find out the reasons for the discontinuation of randomized clinical trials and classify them based on scientific explanations, non-scientific reasons, and determination of the average timing from the date of registration to date of modification and the median time from the date of last revision to date of our analysis.

\section{Materials and Methods}

This was a cross-sectional study where secondary data were extracted from the CTRI website (www.ctri.nic.in) hosted by the Indian Council of Medical Research (ICMR) and the National Institute of Medical Statistics. A crosssectional study is suitable to be used when the main objective is descriptive, and the data collected is once only across the population of interest.

\section{Selection of Trials}

The CTRI database records from 20 July 2007 to 18 December 2019 were accessed at the URL to answer the study's objectives (http://ctri.nic.in/Clinicaltrials/advance searchmain.php). The following search elements were used during the first level of screening, which resulted in a total of 23,129 trials registered in the CTRI: 1) Study Design = "all"; 2) Trial Phase = "all"; 3) Primary Sponsor = "all"; 4) State = "all"; 5) District = "all." When the search was limited to "interventional" only as of the Type of Study, the eligible trials were reduced to 16,579 trials. Finally, when the 
Recruitment Status (Indian) was set as "other (terminated)," this final search led to a list of 243 terminated trials, where the trials which were not yet recruiting or still open to recruitment, suspended, completed, or closed to the recruitment of participants were excluded from this study. As per the CTRI, terminated trials are those trials which are not conducted for some reason (http://ctri.nic.in/Clinicaltrials/ faq.php). The summary of the trial selection is depicted in Figure 1.

\section{Determination of the Availability of Reasons for Termination}

The data of all the 243 terminated trials were tabulated in Microsoft Excel, viewed in detail, and examined further to categorize the trials' termination reasons. The various study characteristics under which the details of the trials were analyzed were the Type of Study, Public Title, Type of Trial, Recruitment Status, Health Condition, Intervention Name, Phase of Trial, Target Sample Size, Countries of Recruitment, Date of First Enrollment, Post Graduate Thesis, Publication Details, Regulatory Clearance Status, Estimated Duration of Trial, Summary, Date of registration, Date of last modification and Reasons for termination.

For further analysis, the reasons for the termination of the various interventional trials were extracted from the summary section and were subdivided into three categories as follows:

1. Scientific - reasons related to efficacy and safety of the intervention

2. Nonscientific - reasons not associated with the intervention

3. Unspecified - reasons which are unclear or with no justification

The analysis of updating the data into the CTRI portal for various terminated trials was assessed. The time to which the data were not updated was calculated from the registration date till the last day of modification on the web page.

Descriptive analyses were conducted for data analysis, where the values are expressed as frequency and percentage for categorical variables and median \pm standard deviation (SD) for numerical variables. Statistical inferences were not conducted because it was only intended to reflect and describe the CTRI results of database data.

\section{Ethical Approval}

The study was approved by the Institutional Ethics Committee of Basni Industrial Area, MIA 2nd Phase, Basni, Jodhpur, Rajasthan 342,005, India (http://www.aiimsjodhpur.edu.in) with ethical certificate reference number: AIIMS/IEC/2020/ 2147 Dated: January-18-2020.

\section{Results}

All the clinical trials from the CTRI database from the inception date till 18 Dec 2019 were included. The total number of studies registered was 23,129, including all types of studies (Interventional, Observational, Post-marketing surveillance, and Bioavailability and bioequivalence studies). Out of 23,129 studies, we could find 16,579 interventional clinical trials posted on the results database, out of which 243 trials $(1.46 \%)$ were listed as terminated. Of these 243 terminated trials, the study characteristics, which were studied, are summarized in Table 1 . The most common type of study were studies involving drug (67.5\%), followed by biologics (10.7\%) and medical device (5.8\%). Most of the trials were in Phase 3 (46.5\%) and followed by Phase 2 (15.6\%). Approximately $14.4 \%$ of the trials did not mention their trial phase. It was also found that $72.8 \%$ of the trials had regulatory clearance from the drug regulatory authorities, while $24.3 \%$ of the trials reported it as "not applicable" (NA), and $0.4 \%$ were awaiting approval. The majority (95.9\%) of the trials were not from the postgraduate thesis. The majority of the terminated trials were from oncology $(17.7 \%)$, followed by endocrine and metabolic disorders $(14 \%)$, cardiology $(7.8 \%)$, orthopedics (7.41\%), and neurology (7\%). The system-wise detailed distribution of various terminated trials is depicted in Figure 2. The median time from the date of registration to the date of modification was 1034 days (minimum=0 day to maximum=3912 days) and the median time from the date of last revision to the date of our analysis was 1329 days (minimum $=2$ days to maximum $=3138$ days).

\section{Reasons for Termination of Trials}

Out of the 243 terminated trials, reasons were given in only 50 (20.6\%) of them. The grounds for termination were categorized into three categories in this study, as explained before. Out of the 50 terminated trials with documented reasons, 15 $(30.0 \%)$ of them had reasons associated with scientific data. The most common reasons were related to safety issues with the product $(14.0 \%, \mathrm{n}=7)$. Another $37(54.0 \%)$ got terminated due to nonscientific reasons, with the most prevalent cause in this category was attributed to a significant delay in 


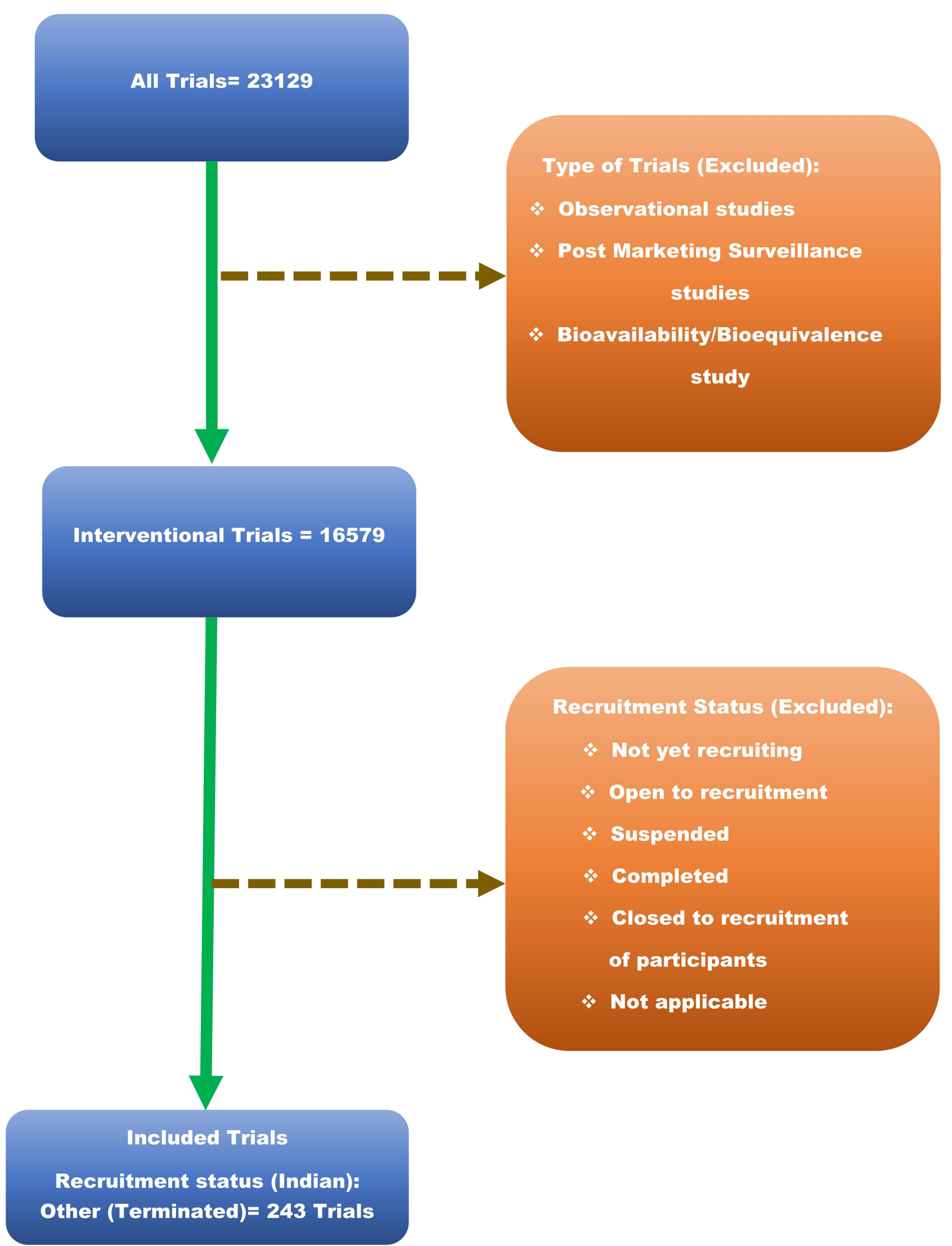

Figure I Schematic diagram of study selection from data elements of Clinical Trial Registry of India used to filter records. 
Table I Study Characteristics of the Terminated Interventional Trials in the Clinical Trial Registry of India $(n=243)$

\begin{tabular}{|c|c|c|c|}
\hline \multicolumn{2}{|c|}{ Study Characteristics } & \multirow{2}{*}{$\begin{array}{l}\text { Frequency } \\
164\end{array}$} & \multirow{2}{*}{$\begin{array}{l}\text { Percentage } \\
67.5\end{array}$} \\
\hline Study Type & Drug & & \\
\hline & Biologics & 26 & 10.7 \\
\hline & Medical device & 14 & 5.8 \\
\hline & Vaccines & 5 & 2.1 \\
\hline & Stem cell & 7 & 2.9 \\
\hline & Ayurveda & 7 & 2.9 \\
\hline & Nutraceuticals & 6 & 2.5 \\
\hline & Cosmetics & I & 0.4 \\
\hline & Physiotherapy & I & 0.4 \\
\hline & Surgical & 4 & 1.6 \\
\hline & anesthesia & & \\
\hline & Diagnostics & I & 0.4 \\
\hline & Homeopathy & 2 & 0.8 \\
\hline & Radiation & I & 0.4 \\
\hline & therapy & & \\
\hline & Process of care & 3 & 1.2 \\
\hline & changes & & \\
\hline & Yoga and & I & 0.4 \\
\hline & naturopathy & & \\
\hline \multirow[t]{8}{*}{ Trial Phase } & Phase I & 13 & 5.3 \\
\hline & Phase 2 & 38 & 15.6 \\
\hline & Phase 3 & 113 & 46.5 \\
\hline & Phase 4 & 16 & 6.6 \\
\hline & Phase $2 / 3$ & 14 & 5.8 \\
\hline & Phase $3 / 4$ & 5 & 2.1 \\
\hline & $\mathrm{Na}$ & 35 & 14.4 \\
\hline & Phase $1 / 2$ & 9 & 3.7 \\
\hline Countries of & Global/India & 108 & 44.4 \\
\hline Recruitment & India & 135 & 55.6 \\
\hline Regulatory & Present & 177 & 72.8 \\
\hline \multirow[t]{4}{*}{ Clearance } & Notified & 3 & 1.2 \\
\hline & NOC & 3 & 1.2 \\
\hline & NA & 59 & 24.3 \\
\hline & Awaited & I & 0.4 \\
\hline \multirow[t]{2}{*}{ PG Thesis } & Yes & 10 & 4.1 \\
\hline & No & 233 & 95.9 \\
\hline \multirow[t]{2}{*}{ Publication } & Yes & 16 & 6.6 \\
\hline & No & 227 & 93.4 \\
\hline
\end{tabular}

recruitment $(16.0 \%, \mathrm{n}=8)$. The other eight $(16.0 \%)$ trials with documented termination reasons were classified as "unspecified." [Figure 3] The details of the reasons are given in Table 2.

\section{Discussion}

This study was conducted to evaluate the terminated clinical trials registered in the CTRI in terms of reasons given for premature terminations. It was observed that the grounds for termination were mentioned for very few clinical trials. Out of all the reasons cited for premature termination, the most frequent were safety issues and recruitment delays.

We could find only $20.6 \%$ of the trials mentioned their reasons for termination, which was shallow. Poor reporting of reasons for premature termination of clinical trials in the CTRI is a grave concern. Since, without knowing the reasons, it is difficult to comment on the rationality of clinical trials' termination. Several studies have shown that reporting reasons for the stop were better reported in other countries' clinical trial registries than the Indian registry. ${ }^{6,13,14}$ The issue of underreporting or erroneous reporting of various parameters in the CTRI is also highlighted in some previous studies. Still, to the best of our knowledge, no data was reported related to the reasons for the trials' termination. ${ }^{10}$ The median time from the last modification date to our data extraction date was 1329 days, which is sufficient time to add any new information, including the reasons for the termination of clinical trials. This shows that there is no obligation for investigators to add such information in the CTRI. It also shows that there is no mechanism in place to nudge investigators to add such details. Not reporting relevant information in the clinical trial registry is not limited to India's clinical trial registry; some underreporting is also observed for other international registries. In the study conducted by Alturki et al for the clinical trials registered in ClinicalTrials.gov, isrctn.com, and additional registries, it was found that many parameters of terminated clinical trials were better reported in the research publications generated out of these clinical trials as compared to the information given in registries. $^{15}$

Most of the reasons for the termination of clinical trials mentioned in the CTRI were nonscientific (54.0\%). We found a "significant delay in recruitment" as the most common nonscientific reason for termination (16.0\%). A study conducted by Williams et al reported an insufficient accrual rate as the lead reason for the termination of trials registered in the ClinicalTrials.gov database. ${ }^{6}$ Baldi et al analyzed the terminated cardiovascular trials in the ClinicalTrials.gov database and reported poor accrual rate to be a significant factor for the early termination of trials. ${ }^{13}$ Various other studies conducted in international clinical trial registries have also reported a "poor accrual rate" as the most common reason for termination. Still, it is not among the frequent reasons mentioned in the CTRI. ${ }^{16,17}$ Low accrual, as a reason, was reported by 


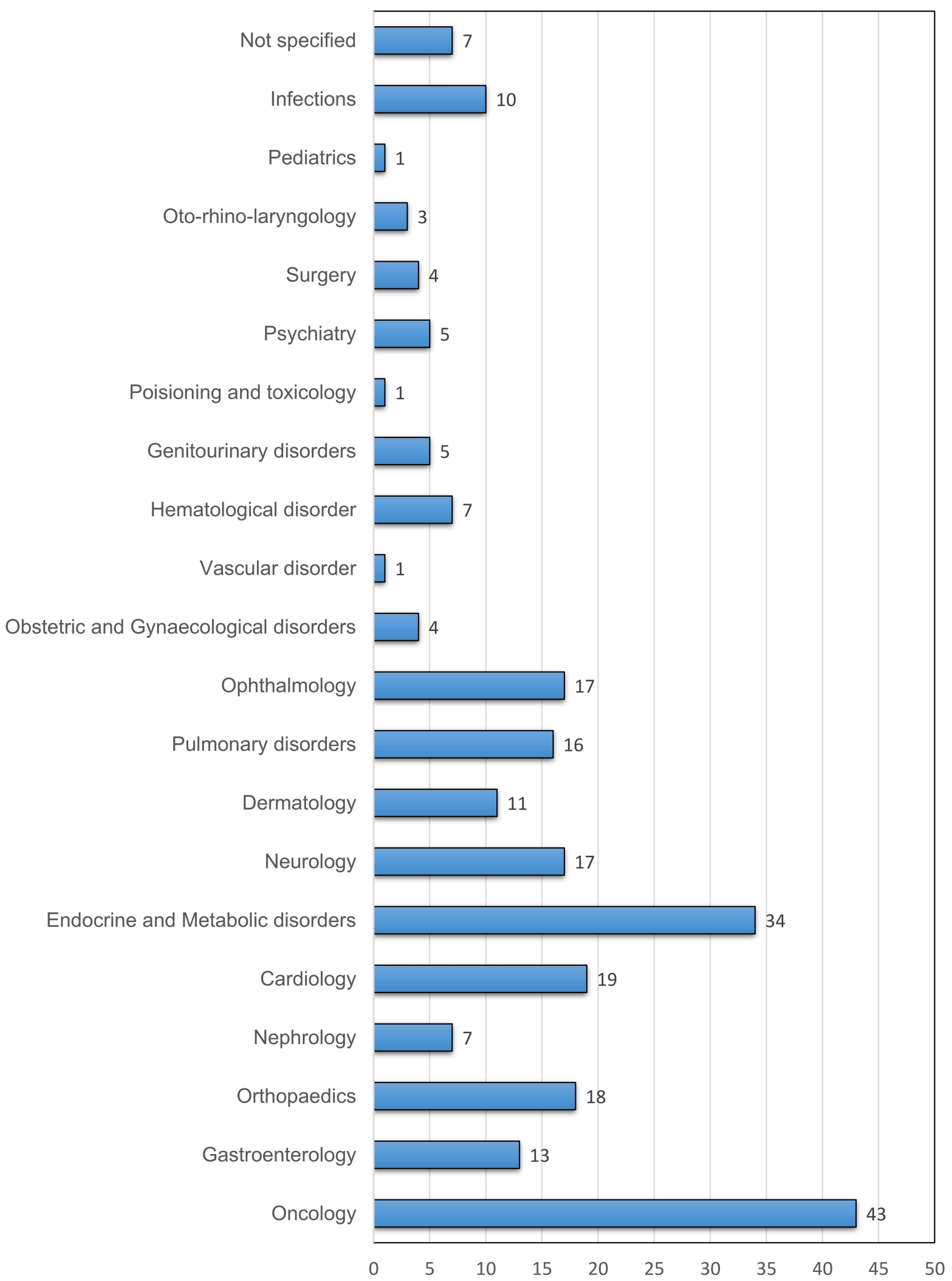

Figure 2 System-wise distribution of terminated clinical trials. 


\section{Reasons for Termination of Interventional Trials in CTRI Database}

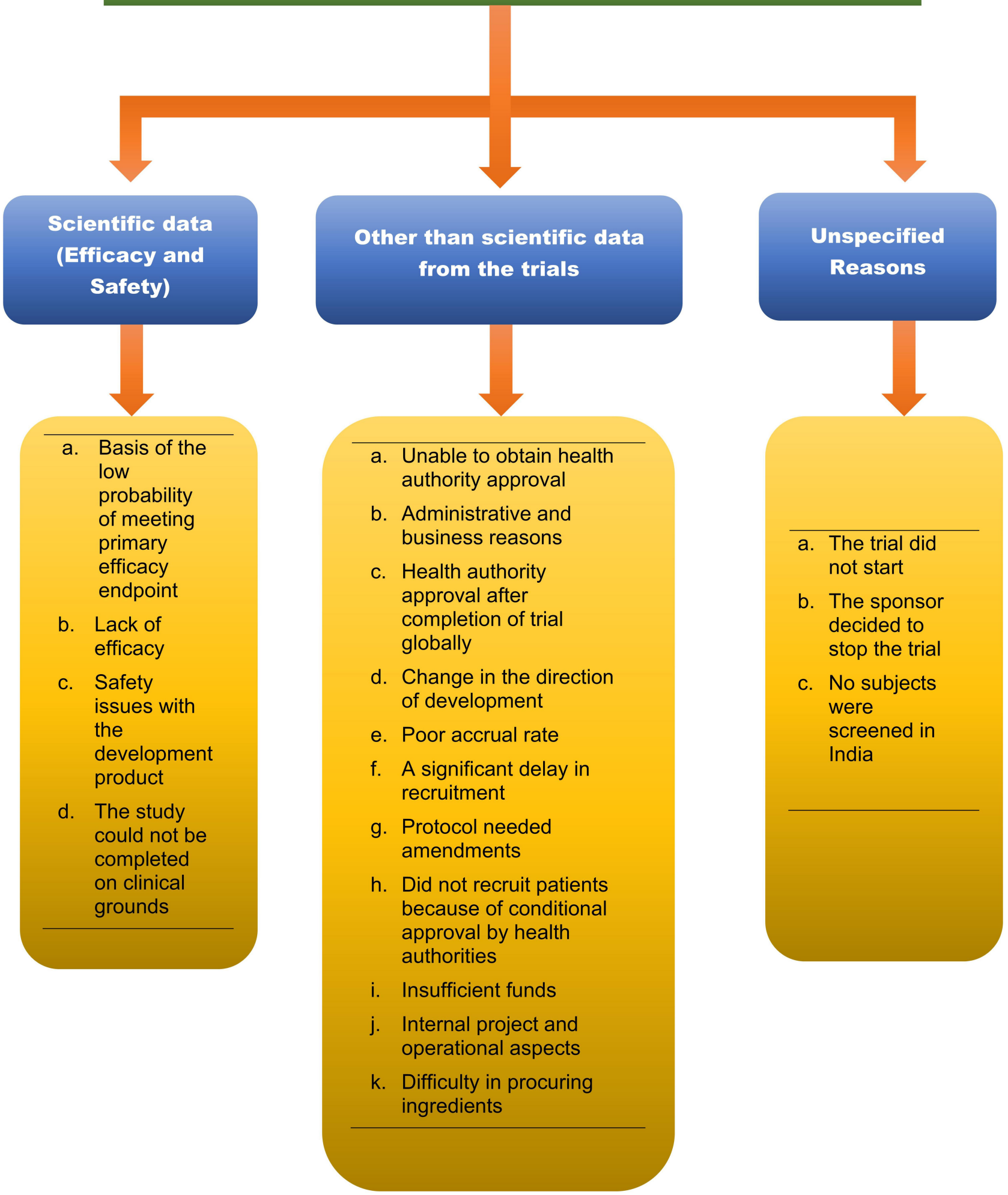

Figure 3 Flowchart summarizing reasons for termination of clinical trials stated in Clinical Trial Registry of India (CTRI). 
Table 2 Reasons for Termination of Trials in the Clinical Trial Registry of India $(n=50)$

\begin{tabular}{|c|c|c|c|c|}
\hline Serial & \multicolumn{2}{|l|}{ Reasons for Termination } & Frequency & $\%$ \\
\hline 1 & $\begin{array}{l}\text { Based on scientific data (efficacy and } \\
\text { safety) }\end{array}$ & $\begin{array}{l}\text { a. Basis of the low probability of meeting primary efficacy } \\
\text { endpoint } \\
\text { b. Lack of efficacy } \\
\text { c. Safety issues with the development product } \\
\text { d. The study could not be completed on clinical grounds }\end{array}$ & $\begin{array}{l}3 \\
4 \\
7 \\
1\end{array}$ & $\begin{array}{l}6 \\
8 \\
14 \\
2\end{array}$ \\
\hline 2 & $\begin{array}{l}\text { Based on other than scientific data from } \\
\text { the trial }\end{array}$ & $\begin{array}{l}\text { a. Unable to obtain health authority approval } \\
\text { b. Administrative and business reasons } \\
\text { c. Health authority approval after completion of trial globally } \\
\text { d. Change in the direction of development } \\
\text { e. Poor accrual rate } \\
\text { f. A significant delay in recruitment } \\
\text { g. Protocol needed amendments } \\
\text { h. Did not recruit patients because of conditional approval by } \\
\text { health authorities } \\
\text { i. Insufficient funds } \\
\text { j. Internal project and operational aspects } \\
\text { k. Difficulty in procuring ingredients }\end{array}$ & $\begin{array}{l}4 \\
3 \\
2 \\
3 \\
1 \\
8 \\
1 \\
1 \\
2 \\
1 \\
1 \\
1\end{array}$ & $\begin{array}{l}8 \\
6 \\
4 \\
6 \\
2 \\
16 \\
2 \\
2 \\
4 \\
2 \\
2\end{array}$ \\
\hline 3 & Unspecified reasons & $\begin{array}{l}\text { a. The trial did not start } \\
\text { b. The sponsor decided to stop the trial } \\
\text { c. No subjects were screened in India }\end{array}$ & $\begin{array}{l}2 \\
3 \\
3\end{array}$ & $\begin{array}{l}4 \\
6 \\
6\end{array}$ \\
\hline
\end{tabular}

only one terminated clinical trial. Some vague reasons like "termination due to an internal project and operational aspect," "termination due to administrative or business reasons," and "study could not be completed due to clinical ground" were also mentioned. Previous few studies conducted by Pak et al (7.3\%), Williams et al (12.4\%), and Pica et al $(8.7 \%)$ have also reported termination due to business reasons as one of the factors for termination. ${ }^{6,11,16}$ Administrators of the CTRI should make investigators aware of the reporting of apparent reasons. Important common reasons should be added to the system so that the investigator can select them during data entry in the registry. Out of reasons mentioned for termination of the trials, only a few reasons like "lack of efficacy," "termination due to safety issues," "poor accrual rate" were justified reasons while termination due to many other reasons could have been avoided by proper planning before initiation of the trial as well as during the trial. ${ }^{18}$

This study has a few limitations. We included all trials categorized as terminated in the CTRI. Still, some trials may be already terminated, but information about their current status is yet to be updated in the system. The trial status discrepancy in the registry and the actual situation is observed for trial registered in ClinicalTrials.gov. ${ }^{19}$
We could not compare the reporting of reasons with other characteristics of trials, e.g., phase of the trial, industrysponsored vs. public organization sponsored, etc., because of less reporting of grounds for termination. This study was conducted based on the information provided in the CTRI; no investigator was contacted to confirm the actual reasons for terminations.

\section{Conclusion}

Based on the current study, it can be concluded that the reasons for termination are not mentioned adequately for the terminated clinical trials in the Clinical Trial Registry of India. Efforts need to be done to motivate investigators to report the reasons for termination in the portal. With the identification of potential barriers to successful study completion, the present study indicates the need to reduce the risk of premature trial discontinuation and save limited research resources. Proper planning of trial before initiation, regular monitoring, and auditing may prevent premature termination of clinical trials and ensure fair use of valuable resources.

\section{Recommendation}

Since randomized clinical trials are eminently resourcedemanding, adequate recruitment strategies, prior 
evaluation, and proper calculations of the anticipated problems can minimize the apprehension associated with trials' planning and conduction. Besides this, CTRI is a valuable database that has proved its worth in improving India's clinical trial record. A few strategies that can improve it are automated reminder emails sent to the applicant if incompletely filled data or missing timely needed updates on the portal. The update on study results should be mandatory if the trial is completed or terminated for some reason, which is currently missing from the CTRI portal.

\section{Key Messages}

- The present study provides valuable insights into the prevalence and features of randomized clinical trials that were terminated due to various reasons

- The reasons for the termination of the trials should be mentioned in the CTRI database, which will reduce the chances of subsequent researchers to repeat the similar mistake in their study

- The trials should be appropriately planned by priorly assessing all the available resources and feasibility to minimize the chances of premature termination and wastage of valuable resources

- Dedicated staffs should regularly monitor the CTRI database, and reminders or mails should be sent to the defaulters in case of incomplete information in the database

\section{Acknowledgment}

The authors are grateful to Professor (Dr.) M.S. Razzaque, MBBS, Ph.D. of Lake Erie College of Osteopathic Medicine, Pennsylvania, USA. He has taken special care regarding the English language.

\section{Author Contributions}

All authors made substantial contributions to conception and design, acquisition of data, or analysis and interpretation of data; took part in drafting the article or revising it critically for important intellectual content; agreed to submit to the current journal; gave final approval of the version to be published; and agree to be accountable for all aspects of the work.

\section{Funding}

This paper was not funded.

\section{Disclosure}

The authors declare that they do not have any financial involvement or affiliations with any organization, association, or entity directly or indirectly with the subject matter or materials presented in this article. This includes honoraria, expert testimony, employment, ownership of stocks or options, patents or grants received or pending, or royalties. The authors report no conflicts of interest for this work.

\section{References}

1. Clinical trials: Overview. World Health Organization. Available from: https://www.who.int/health-topics/clinical-trials/\#tab=tab_1. Accessed June 20, 2020

2. Webber S, Prouse C. The new gold standard: the rise of randomized control trials and experimental development. Econ Geogr. 2018;94 (2):166-187. doi:10.1080/00130095.2017.1392235

3. Collier R. Legumes, lemons and streptomycin: a short history of the clinical trial. CMAJ. 2009;180(1):23-24. doi:10.1503/cmaj.081879

4. Bhatt A. Evolution of clinical research: a history before and beyond James Lind. Perspect Clin Res. 2010;1(1):6-10.

5. Szajewska H. Evidence-based medicine and clinical research: both are needed, neither is perfect. Ann Nutr Metab. 2018;72(Suppl 3):13-23. doi:10.1159/000487375

6. Williams R, Tse T, DiPiazza K, Zarin D, Briel M. Terminated trials in the ClinicalTrials.gov results database: evaluation of availability of primary outcome data and reasons for termination. PLoS One. 2015;10(5):e0127242. doi:10.1371/journal.pone.0127242

7. ClinicalTrials.gov Background. Available from: https:/clinicaltrials. gov/ct2/about-site/background. Accessed June 22, 2020.

8. Clinical Trial Registry of India [homepage on the Internet]. National Institute of Medical Statistics. Available from: http://ctri.nic.in/ Clinicaltrials/cont1.php. Accessed June 22, 2020.

9. Vardhana Rao M, Maulik M, Gupta J, et al. Clinical Trials Registry India: an overview and new developments. Indian J Pharmacol. 2018;50(4):208. doi:10.4103/ijp.IJP_153_18

10. Pillamarapu M, Mohan A, Saberwal G. An analysis of deficiencies in the data of interventional drug trials registered with Clinical Trials Registry-India. Trials. 2019;20(1):535. doi:10.1186/s13063-0193592-0

11. Pak TR, Rodriguez MD, Roth FP. Why clinical trials are terminated. BioRxiv. 2015;021543. doi:10.1101/021543

12. Van Lent M, IntHout J, Out H. Differences between information in registries and articles did not influence publication acceptance. J Clin Epidemiol. 2015;68(9):1059-1067. doi:10.1016/j.jclinepi.2014.11.019

13. Baldi I, Lanera C, Berchialla P, Gregori D. Early termination of cardiovascular trials as a consequence of poor accrual: analysis of ClinicalTrials.gov 2006-2015. BMJ Open. 2017;7(6):e013482. doi:10.1136/bmjopen-2016-013482

14. Bernardez-Pereira S, Lopes RD, Carrion MJ. Prevalence, characteristics, and predictors of early termination of cardiovascular clinical trials due to low recruitment: insights from the ClinicalTrials.gov registry. Am Heart J. 2014;168(2):213-219. doi:10.1016/j. ahj.2014.04.013

15. Alturki R, Schandelmaier S, Olu KK, et al. Premature trial discontinuation often not accurately reflected in registries: comparison of registry records with publications. $J$ Clin Epidemiol. 2017;81:56-63. doi:10.1016/j.jclinepi.2016.08.011

16. Pica N, Bourgeois F. Discontinuation and nonpublication of randomized clinical trials conducted in children. Pediatrics. 2016;138(3): e20160223. doi:10.1542/peds.2016-0223 
17. Chapman SJ, Shelton B, Mahmood H, Fitzgerald JE, Harrison EM, Bhangu A. Discontinuation and non-publication of surgical randomized controlled trials: an observational study. Version 2. BMJ. 2014;349:g6870. doi:10.1136/bmj.g6870

18. Ioannidis JP. Clinical trials: what a waste. $B M J .2014 ; 349(\operatorname{dec} 1014)$ : g7089. doi:10.1136/bmj.g7089
19. Jones CW, Safferman MR, Adams AC, Platts-Mills TF. Discrepancies between ClinicalTrials.gov recruitment status and actual trial status: a cross-sectional analysis. BMJ Open. 2017;7 (10):e017719. doi:10.1136/bmjopen-2017-017719

\section{Publish your work in this journal}

The Open Access Journal of Clinical Trials is an international, peerreviewed, open access journal publishing original research, reports, editorials, reviews and commentaries on all aspects of clinical trial design, management, legal, ethical and regulatory issues, case record form design, data collection, quality assurance and data auditing methodologies. The manuscript management system is completely online and includes a very quick and fair peer-review system, which is all easy to use. Visit http://www.dovepress.com/testimonials.php to read real quotes from published authors. 